\title{
Socio-demographic characteristics associated with hospitalization for sepsis among adults in Canada: a Census-linked cohort study Caractéristiques sociodémographiques associées à l'hospitalisation suite à un sepsis chez les adultes au Canada : une étude de cohorte liée au Recensement
}

\author{
Deirdre A. Hennessy, PhD (D) - Andrea Soo, PhD • Daniel J. Niven, MD, MSc • \\ Rachel J. Jolley, MSc • Juan Posadas-Calleja, MD, MSc • Henry T. Stelfox, MD, PhD • \\ Christopher J. Doig, MD, MSc
}

Received: 28 April 2019/Revised: 16 October 2019/Accepted: 22 October 2019/Published online: 2 December 2019

(C) Canadian Anesthesiologists' Society 2019

\begin{abstract}
Purpose Sepsis is a considerable health system burden. Population-based epidemiological surveillance of sepsis is limited to basic data available in administrative databases. We sought to determine if routinely collected Census data, linked to hospitalization data, can provide a broad sociodemographic profile of patients admitted to Canadian hospitals with sepsis.

Methods Linking the 2006 long-form Canadian Census (most recent available for linkage) to the Discharge
\end{abstract}

This article is accompanied by an editorial. Please see Can J Anesth 2020; 67: this issue.

Electronic supplementary material The online version of this article (https://doi.org/10.1007/s12630-019-01536-z) contains supplementary material, which is available to authorized users.

\section{A. Hennessy, PhD ( $ه)$}

Health Analysis Division, Statistics Canada, 100 Tunney's

Pasture Driveway, Ottawa, ON K1A 0T6, Canada

e-mail: deirdre.hennessy@canada.ca

Department of Community Health Sciences, University of Calgary, Calgary, AB, Canada

\author{
A. Soo, $\mathrm{PhD} \cdot$ J. Posadas-Calleja, MD, MSc \\ Department of Critical Care Medicine, University of Calgary and \\ Alberta Health Services, Calgary, AB, Canada \\ D. J. Niven, MD, MSc · R. J. Jolley, MSc . \\ H. T. Stelfox, MD, PhD - C. J. Doig, MD, MSc \\ Department of Community Health Sciences, University of \\ Calgary, Calgary, AB, Canada
}

Department of Critical Care Medicine, University of Calgary and Alberta Health Services, Calgary, AB, Canada
Abstract Data from 2006/2007 to 2008/2009, we created a population-based cohort of approximately 3,433,900 Canadians. Patients admitted to hospital with sepsis were identified using the Canadian Institute for Health Information administrative data definition. Agestandardized hospital admission rates for sepsis were calculated. Multivariable modelling was used to examine the relationship between Census characteristics and hospitalization with sepsis.

Results $O f$ those individuals successfully linked to the 2006 long-form Canadian Census, 10,400 patients of $18 \mathrm{yr}$ and older were admitted to hospital with sepsis between the fiscal years 2006/2007 and 2008/2009. These individuals represented a weighted count of approximately 49,000 Canadians from all provinces and territories, excluding Quebec. The age-standardized rate of sepsis hospitalization was 96 cases/100,000 population. Of these, 37/100,000 cases were classified as severe sepsis. The association of Census characteristics with sepsis hospitalization varied with age. In all age-specific models, male sex, never being married, visible minority status, having functional limitations, and not being in the labour force were associated with an increased odds of hospital admission.

Conclusions Census data identified broad sociodemographic risk factors for admission to hospital with sepsis. Consideration should be given to incorporating Census data linked to administrative hospital data in population-based epidemiologic surveillance. 


\section{Résumé}

Objectif Le sepsis constitue un fardeau considérable pour le système de santé. La surveillance épidémiologique du sepsis sur la population se limite aux données de base disponibles dans les bases de données administratives. Nous avons cherché à déterminer si, en liant les données $d u$ Recensement aux données d'hospitalisation, cet ensemble pouvait nous procurer un large profil sociodémographique des patients admis pour traiter un état septique dans les hôpitaux canadiens.

Méthode En liant le Recensement canadien de 2006 (le plus récent disponible aux fins de liaison) aux Données de la Base de données sur les congés des patients de 2006/ 2007 à 2008/2009, nous avons créé une cohorte fondée sur une population d'environ 3433900 Canadiens. Les patients admis à l'hôpital suite à un sepsis ont été identifiés à l'aide de la définition de l'Institut canadien d'information sur la santé sur les données administratives. Les taux d'admission à l'hôpital standardisés pour l'âge ont été calculés pour le sepsis. Des modèles multivariés ont été utilisés pour examiner la relation entre les caractéristiques du Recensement et l'hospitalisation due à un état septique.

Résultats Parmi les individus qui ont pu être liés au Recensement canadien de 2006, 10400 patients de 18 ans ou plus ont été admis à l'hôpital en raison d'un sepsis entre les années financières 2006/2007 et 2008/2009. Ces personnes représentaient un décompte pondéré d'environ 49000 Canadiens provenant de toutes les provinces et territoires, à l'exclusion du Québec. Le taux d'hospitalisation due au sepsis standardisé pour l'âge était de 96 cas $/ 100000$ personnes. Parmi ces cas, 37/100 000 ont été catégorisés comme un état septique grave. L'association entre les caractéristiques du Recensement et l'hospitalisation due au sepsis variait en fonction de l'âge. Dans tous les modèles spécifiques en fonction de l'âge, le sexe masculin, le fait de n'avoir jamais été marié, un statut de minorité visible, des limitations fonctionnelles et le fait de ne pas faire partie de la population active étaient associés à une probabilité plus élevée d'admission à l'hôpital.

Conclusion Les données du Recensement ont permis d'identifier des facteurs de risque sociodémographiques d'admission à l'hôpital pour traiter un état septique. Il faudrait envisager d'intégrer des données du Recensement liées aux données administratives hospitalières pour exercer une surveillance épidémiologique fondée sur la population.

\section{Introduction}

Sepsis is defined as organ dysfunction resulting from infection, and is a critical condition with high mortality rates. ${ }^{1}$ Global estimates, based mainly on data from selected high-income countries, and extrapolated for lowincome countries, suggest that there are approximately 32 million sepsis cases annually, 19 million of which are severe. These cases result in an estimated 5 million deaths worldwide. $^{2}$ The Canadian Institute for Health Information (CIHI) has estimated that there are approximately 30,000 sepsis hospitalizations annually in Canada, ${ }^{3,4}$ while a 2011 study of vital statistics data showed that 1 in 18 deaths among Canadians involved sepsis as the main or underlying cause. ${ }^{5}$ Survivors of sepsis are often left with long-term physical and cognitive deficits, and reduced quality of life, ${ }^{6}$ contributing to increased cost, extended hospitalization, and intensive post-discharge healthcare utilization. $^{7}$ Despite the burden of sepsis, public and political recognition of the disease is limited. ${ }^{8,9}$ As a result, the World Health Organization recognized sepsis as a global health priority in 2017 and adopted a resolution on improving the prevention, diagnosis, and management of sepsis. ${ }^{10}$ They recommended that the development of monitoring and evaluation tools as well as epidemiological surveillance systems should be the cornerstones of the sepsis strategy.

There are a number of important challenges with sepsis surveillance, even in high-income countries such as Canada. $^{2}$ At the population level, a practical and costefficient method to collect information about sepsis hospitalizations and mortality is through retrospective review of hospital records using International Classification of Disease (ICD) coding strategies. Nevertheless, hospital records alone contain incomplete socio-demographic information, limiting their utility for epidemiological surveillance. ${ }^{11-14}$

Another method has been to use ICD coded death certificates to investigate clustering of sepsis mortality by geographic area. ${ }^{15,16}$ While these studies have revealed geographic patterns in sepsis mortality in the United States, they were ecological in nature and could not directly investigate any associations between socio-demographic exposures and outcomes. ${ }^{15,16}$

An alternative approach to sepsis surveillance is to utilize linked population-based data. Specifically, population-based data sources, including the 2006 Canadian Census, have been linked to the CIHI Discharge Abstract Data (DAD) at Statistics Canada, to 
facilitate population health and health services research. ${ }^{17-19}$ The data collected in the long-form Canadian Census provide a rich multidimensional look at the Canadian population, including many important social determinants of health. Combined with clinical information available in the DAD, these data afford a unique opportunity to examine detailed socio-demographic characteristics of patients admitted to hospital with sepsis. Using Census-linked data provides antecedent information about sepsis patients in line with a paradigm where sepsis is conceptualized as a preventable public health problem. ${ }^{20}$ This is an important step towards identifying modifiable risk factors and high-risk groups to target future primary and secondary sepsis prevention strategies and includes considering population risk factors available through sources such as Census data.

The primary purpose of this study, achieved by linking data from the 2006 long-form Canadian Census with the CIHI DAD, was to identify socio-demographic factors in adults aged $18 \mathrm{yr}$ and older, associated with admission to a Canadian hospital with sepsis. A secondary objective was to compare the outcomes in patients hospitalized for sepsis with those hospitalized for other reasons.

\section{Methods}

\section{Study design}

This study was a retrospective linked cohort design utilizing the 2006 long-form Canadian Census linked to the DAD from 2006/2007 to 2008/2009. This was the most current Census-DAD linkage completed at Statistics Canada. Approval for this linkage was granted by Statistics Canada's Executive Management Board. ${ }^{21}$

\section{Data sources}

\section{Census of Canada}

The 2006 Census of Canada was administered by Statistics Canada on May 16th 2006 and collected information using both short- and long-form questionnaires. ${ }^{22}$ Eighty percent of households received the short-form, containing eight questions about birth date, sex, marital status, and language spoken by all household members. Twenty percent of households received the long-form, containing 53 questions on topics including income, education, employment, ethnicity, visible minority status, immigrant status, and functional limitations. The 2006 Census of Canada represented 95-97\% of the non-institutionalized population of the Canadian provinces and $93-94 \%$ of the non-institutionalized population in the territories. ${ }^{23}$

\section{Discharge abstract database}

CIHI compiles the DAD, which is a national database containing demographic, administrative, and clinical data on hospital discharges across Canada, excluding Quebec. CIHI receives data directly from all public hospitals in every province and territory covered. Re-abstraction studies have found that non-clinical data elements are of a high quality and that the clinical data captured by the DAD are consistently reported. ${ }^{24,25}$ The DAD clinical data include 25 fields of ICD version 10 coded diagnoses and 20 fields of Canadian Classification of Interventions coded procedures.

\section{Linkage methods}

An hierarchical deterministic linkage approach was used to link Census respondents to the DAD from 2006/2007 to $2008 / 2009$. The linkage process has been described in detail and validated by Rotermann et al., who found that the linked file represented approximately $80 \%$ of hospitalizations during the time period. ${ }^{17}$ The 2006 Census linked to the DAD cohort has previously been used for research. ${ }^{18,19}$

\section{Study sample}

The study sample consisted of adult patients $18 \mathrm{yr}$ and older admitted to Canadian hospitals between 2006/2007 and 2008/2009 (excluding Quebec), who successfully linked to the 2006 long-form Canadian Census. Patients admitted with sepsis (defined below) were compared with those admitted for all other diagnoses, excluding patients admitted to give birth. Patients in the study sample could have been hospitalized more than once; for analysis, only one record per patient was retained. For those admitted with sepsis, the first hospital record containing a diagnosis of sepsis was retained. For those admitted for reasons other than sepsis, the first hospital record was retained. The eFigure available as Electronic Supplementary Material (ESM) shows the study flow chart.

Defining sepsis and severe sepsis

Sepsis was defined using an existing administrative data definition developed by $\mathrm{CIHI}^{3,4}$ and based on previous studies by Angus et al. and others. ${ }^{26-28}$ A patient was identified as having an admission for sepsis if any one of the ICD-10-CA codes listed in eTable 1, available as ESM, were present in any of the 25 diagnosis coding fields of the DAD record. Severe sepsis was indicated by the combination of a sepsis code with at least one organ dysfunction code (see eTable 1 available as ESM). 
Primary outcome

Hospital admission with a diagnosis of sepsis was the main outcome of interest in this analysis.

\section{Secondary outcome}

In-hospital death among patients admitted with sepsis was the secondary outcome of interest. Other secondary outcomes of interest included admission to a special care unit, special care unit length of stay, hospital length of stay and discharge disposition (see eTable 2 available as ESM for a more detailed description).

\section{Exposures}

The covariates are described in detail in eTable 2 (available as ESM). The exposures studied in relation to hospital admission with a diagnosis of sepsis were Census characteristics, including age, sex, income, education, marital status, visible minority status, immigrant status, employment, and location of residence. We also examined Indigenous identity. The 2006 Census gathered information on whether a person self-identified with Aboriginal peoples of Canada. In this document, the term "Indigenous" is used in place of "Aboriginal". We further categorized identity by a previously used breakdown ${ }^{18}$ in descriptive analysis (First Nations people living on reserve, First Nations people living off reserve, Métis, Inuit, and other or multiple Indigenous identity). For the calculation of rates and multivariable modelling "Indigenous identity" was used as a dichotomous variable because of small sample sizes in some of the groups (see eTable 2 available as ESM for more details).

These Census variables were chosen for study because they provide a broad description of the socio-demographic characteristics of the Canadian population and are not typically available in health administrative data. Many of these variables have been identified as important social determinants of health for the Canadian population. In addition, the population groups identified here, such as visible minorities, immigrants, and Indigenous populations, may experience a greater burden of health problems because of inequalities in the social determinants of health. $^{29,30}$

\section{Statistical analysis}

Missing values in the Census data were imputed during processing. ${ }^{23}$ The DAD records were screened for missing postal code, birthdate, and sex in advance of being made available for linkage, and approximately $0.8 \%$ of records were excluded. None of the DAD records linked to the
Census data were missing the main diagnosis field. Descriptive statistics (proportion with $95 \%$ confidence interval $[\mathrm{CI}]$ and medians [interquartile ranges (IQR)], as appropriate) were used to compare patients hospitalized with and without a sepsis diagnosis. Crude and agestandardized hospitalization rates for sepsis were calculated by Census characteristics. Estimates were directly age-standardized to the 2006 population.

Multivariable logistic regression models were used to investigate the association between Census characteristics and hospital admission for sepsis. Variables were not individually screened for inclusion in the multivariable models; all Census variables considered important a priori were entered into the model. Variables were not eliminated from the model if they were found to be non-significant. Initially sex-specific models were constructed but showed very similar patterns of associations among men and women, so sex was included as a covariate in the models. A model with interaction terms between age and Census characteristics found strong evidence of effect modification by age, and as a result three age-specific models were run: model 1 for 18-34 yr old; model 2 for 35-64 yr old; and model 3 for $65 \mathrm{yr}$ and older. The age groups were chosen to enable the clinical interpretability of the results. A detailed description of the other variables included in the models can be found in eTable 2 (available as ESM).

Multivariable-adjusted age-specific mortality rates were also calculated for patients hospitalized with and without a sepsis diagnosis. These models were adjusted for additional socio-demographic and clinical variables including sex, income, education, marital status, visible minority status, Indigenous status, immigrant status, difficulties with activities of daily living, labour force participation, Charlson score, severe sepsis status, and special care unit stay.

In the present study, all estimates were calculated using the Census weights. The long-form Census is a $20 \%$ sample of the Canadian population and as such may be subject to sampling error, therefore use of the Census weights is recommended for analyses of these data. Using the Census weights allows us to make inferences about the Canadian population by compensating for unequal probabilities of sampling and non-response and adjusting the weighted sample distributions for key variables of interest (for example age, sex, and geography) to make it conform to a known population distribution. ${ }^{31,32}$ The Census weights were not adjusted for linkage eligibility. All analyses were conducted using SAS 9.3 (SAS Institute, Cary, NC, USA) and Stata 13 (StataCorp, College Station, TX, USA). 


\section{Results}

Creating the population-based cohort

Of the 4,652,700 individuals that had a completed 2006 long-form Canadian Census and were linked to the DAD, $3,433,900$ individuals remained in our population-based cohort after excluding Census and hospitalization records in individuals less than $18 \mathrm{yr}$ of age, hospitalizations occurring outside the study period, hospitalizations for births, and non-unique hospitalizations. Of the 3,433,900 individuals aged $18 \mathrm{yr}$ and older, 10,400 were hospitalized with sepsis between 2006/2007 and 2008/2009 (see the eFigure available as ESM).

Socio-demographic and clinical characteristics

These respondents represented a weighted count of approximately 49,000 Canadians from all provinces and territories in Canada, excluding Quebec. Forty-four percent of patients admitted to hospital with sepsis were women compared with $52.71 \%$ admitted to hospital for all other reasons (excluding birth-related admissions). The median age of patients admitted with sepsis was $68 \mathrm{yr}$ compared with $60 \mathrm{yr}$ for patients admitted for other reasons. Further socio-demographic and clinical characteristics of respondents admitted to hospital with and without sepsis, as well the overall population-based cohort, are detailed in Table 1 and eTable 3 (available as ESM).

\section{Rates of sepsis hospitalization per 100,000 population}

The overall average annual age-standardized rate of sepsis hospitalization in Canada was 96 cases per 100,000 population in the years 2006/2007-2008/2009. Severe sepsis cases comprised almost $40 \%$ of those cases with an average annual rate of 37 cases/100,000 population. Overall, rates of sepsis hospitalization increased with age and were higher among men than women, while agestandardized rates varied across Census characteristics; notably, rates increased with decreasing income quintile and lower level of education. Sepsis hospitalization rates were higher among Indigenous individuals, as well as those reporting functional limitations and those not in the labour force (Table 2).

Census characteristics associated with sepsis hospitalization

The association between Census characteristics and sepsis hospitalization was examined in a series of multivariable models. Sex-specific models showed very similar patterns of associations among men and women, and therefore were not presented separately; however, sex was included as a covariate. A model with interaction terms between age and Census characteristics found strong evidence of effect modification by age, and as a result three age-specific models were run; model 1 for 18-34 yr old; model 2 for 35-64 yr old; and model 3 for 65 yr and older. Within all the age-specific models, the term for age continued to be statistically significant, indicating that with increasing age the odds of being hospitalized with sepsis increased. In all three age-specific models, men were more likely than women to be hospitalized for sepsis, with the strongest association observed in model 3 ( $\geq 65 \mathrm{yr}$; odds ratio, 1.52; 95\% CI, 1.48 to 1.56 ) (Table 3 ).

In terms of Census characteristics, different associations emerged as statistically significant by age group. Among 18-34 yr olds, marital status, visible minority status, having functional limitations, and not being in the labour force were all factors associated with an increased odds of sepsis hospitalization (Table 3). Among 35-64 year olds, the same factors, in addition to income, education, Indigenous identity, and living in an urban location were associated with an increased odds of sepsis hospitalization (Table 3). In the oldest age group, all Census variables except income were associated with an increased odds of sepsis hospitalization (Table 3). Notably, being a member of a visible minority and having functional limitations had a significant impact on the odds of sepsis hospitalization in all three models with the effect size attenuated with increasing age. A similar pattern was seen for employment.

Length of stay and hospital outcomes among sepsis and non-sepsis patients

Patients hospitalized with sepsis were more often admitted to special care units (45.61\% vs $11.97 \%)$ and had longer median lengths of stay in both special care units $(5.42 \mathrm{vs}$ 2.08 days) and hospital (10 vs 3 days) (Table 4).

Among patients hospitalized with sepsis, there were 3,200 deaths in hospital, representing a weighted count of 15,665 (95\% CI, 15,064 to 16,265) deaths across Canada, except Quebec. The estimated overall crude hospital mortality rate among those hospitalized with sepsis was $31.95 \%$ (95\% CI, 31.54 to 32.37 ), compared with $3.03 \%$ (95\% CI, 3.00 to 3.05) for those hospitalized for all other reasons (excluding birth-related admissions) (see Table 4). Crude mortality rates varied by age group, from $9.48 \%$ (95\% CI, 6.42 to 13.79 ) among patients aged 18-34 yr to $39.31 \%$ (95\% CI, 37.94 to 40.72$)$ in patients aged $65 \mathrm{yr}$ and older (Table 4). Multivariable adjusted mortality rates by age group are presented in eTable 4 (available as ESM) for comparison. 
Table 1 A summary of socio-demographic and clinical characteristics of 2006 long-form Census respondents hospitalized for sepsis, compared with those hospitalized for other reasons, as well as the overall population-based cohort (including those not hospitalized), 2006 Census-Discharge Abstract Database study cohort, Canada excluding Quebec, 2006/2007 through 2008/2009

\begin{tabular}{|c|c|c|c|c|}
\hline Variable & $\begin{array}{l}\text { Sepsis hospitalizations } \\
\text { ( } n=10,400 \text { individuals })\end{array}$ & $\begin{array}{l}\text { Non-sepsis hospitalizations } \\
\text { ( } n=406,000 \text { individuals) }\end{array}$ & $\begin{array}{l}\text { Overall population-based cohort } \\
(n=3,433,900 \text { individuals })\end{array}$ & \\
\hline \multicolumn{5}{|c|}{ Socio-demographic characteristics } \\
\hline $\begin{array}{l}\text { Weighted count ('000) } \\
(95 \% \mathrm{CI})\end{array}$ & $49.02(47.90$ to 50.07$)$ & $1,944.57(1,941.31$ to $1,947.83)$ & $16,869.00(16,859.68$ to $16,873.18)$ & \\
\hline Sex (female), \% (95\% CI) & $44.04(42.97$ to 45.12$)$ & $52.71(52.54$ to 52.88$)$ & $50.13(50.07$ to 50.19$)$ & $P<0.001^{*}$ \\
\hline Age, mean $(95 \% \mathrm{CI})$ & $65.74(65.39$ to 66.08$)$ & $58.88(58.82$ to 58.95$)$ & $46.80(46.78$ to 46.82$)$ & $P<0.001$ \\
\hline Age, median [IQR] & $68[56-78]$ & $60[46-74]$ & $46[33-58]$ & \\
\hline \multicolumn{5}{|l|}{ Income, \% (95\% CI) } \\
\hline Quintile 1 (lowest) & $19.63(18.79$ to 20.51$)$ & $17.16(17.03$ to 17.29$)$ & $16.02(15.97$ to 16.06$)$ & $P<0.001$ \\
\hline Quintile 5 (highest) & $15.13(14.36$ to 15.93$)$ & 18.54 (18.41 to 18.67$)$ & $22.82(22.77$ to 22.87$)$ & $P<0.001$ \\
\hline \multicolumn{5}{|l|}{ Education, \% (95\% CI) } \\
\hline $\begin{array}{l}\text { Did not graduate from high } \\
\text { school }\end{array}$ & 37.46 (36.42 to 38.52$)$ & $30.23(30.07$ to 30.39$)$ & $19.65(19.61$ to 19.70$)$ & $P<0.001$ \\
\hline \multicolumn{5}{|l|}{ Marital status, \% (95\% CI) } \\
\hline Never married & $11.99(11.29$ to 12.73$)$ & $15.08(14.59$ to 15.20$)$ & $28.24(28.19$ to 28.30$)$ & $P<0.001$ \\
\hline \multicolumn{5}{|c|}{ Visible minority group, $\%(95 \% \mathrm{CI})$} \\
\hline Not a visible minority & $84.66(83.87$ to 85.43$)$ & $86.68(86.56$ to 86.79$)$ & $86.63(86.51$ to 86.74$)$ & $P<0.001$ \\
\hline \multicolumn{5}{|c|}{ Indigenous identity ${ }^{\dagger}, \%(95 \% \mathrm{CI})$} \\
\hline Any Indigenous identity & $4.95(4.55$ to 5.38$)$ & $4.11(4.05$ to 4.17$)$ & 3.47 (3.45 to 3.49$)$ & $P<0.001$ \\
\hline \multicolumn{5}{|l|}{ Immigrant status, $\%(95 \% \mathrm{CI})$} \\
\hline Immigrant & $29.79(28.79$ to 30.81$)$ & $24.76(24.61$ to 24.91$)$ & $24.88(24.73$ to 25.03$)$ & $P<0.001$ \\
\hline \multicolumn{5}{|c|}{ Functional limitations, \% (95\% CI) } \\
\hline Often & $31.84(30.83$ to 32.85$)$ & $18.48(18.34$ to 18.61$)$ & $18.80(18.67$ to 18.94$)$ & $P<0.001$ \\
\hline \multicolumn{5}{|l|}{ Employment, \% (95\% CI) } \\
\hline Not in the labour force & $72.02(71.02$ to 72.98$)$ & $53.96(53.78$ to 54.13$)$ & $54.40(54.23$ to 54.57$)$ & $P<0.001$ \\
\hline \multicolumn{5}{|c|}{ Living in an urban location, $\%(95 \% \mathrm{CI})$} \\
\hline Urban & 79.84 (78.97 to 80.68$)$ & $76.30(76.15$ to 76.45$)$ & $80.84(80.80$ to 80.89$)$ & $P<0.001$ \\
\hline \multicolumn{5}{|l|}{ Clinical characteristics } \\
\hline \multicolumn{5}{|c|}{ Charlson score category, \% (95\% CI) } \\
\hline 0 & $31.62(30.61$ to 32.64$)$ & $71.48(71.32$ to 71.63$)$ & $96.51(96.49$ to 96.53$)$ & $P<0.001$ \\
\hline $1-2$ & $17.26(16.46$ to 18.09$)$ & $12.63(12.52$ to 12.74$)$ & $1.50(1.49$ to 1.52$)$ & $P<0.001$ \\
\hline$\geq 3$ & $51.12(50.04$ to 52.21$)$ & $15.89(15.77$ to 16.02$)$ & 1.98 (1.96 to 1.99$)$ & $P<0.001$ \\
\hline Severe sepsis, \% (95\% CI) & 39.09 (38.05 to 40.16$)$ & $\mathrm{n} / \mathrm{a}$ & $\mathrm{n} / \mathrm{a}$ & $\mathrm{n} / \mathrm{a}$ \\
\hline \multicolumn{5}{|c|}{ Count of organ systems failing, \% (95\% CI) } \\
\hline 0 & $60.90(59.84$ to 61.95$)$ & $\mathrm{n} / \mathrm{a}$ & $\mathrm{n} / \mathrm{a}$ & $\mathrm{n} / \mathrm{a}$ \\
\hline 1 & $24.52(23.60$ to 25.47$)$ & $\mathrm{n} / \mathrm{a}$ & $\mathrm{n} / \mathrm{a}$ & $\mathrm{n} / \mathrm{a}$ \\
\hline 2 & 10.55 (9.90 to 11.23$)$ & $\mathrm{n} / \mathrm{a}$ & $\mathrm{n} / \mathrm{a}$ & $\mathrm{n} / \mathrm{a}$ \\
\hline $3+$ & $4.02(3.63$ to 4.46$)$ & $\mathrm{n} / \mathrm{a}$ & $\mathrm{n} / \mathrm{a}$ & $\mathrm{n} / \mathrm{a}$ \\
\hline $\begin{array}{l}\text { Any of the selected } \\
\text { procedures } ¥ \% \text { (95\% CI) }\end{array}$ & $34.62(33.59$ to 35.66$)$ & $\mathrm{n} / \mathrm{a}$ & $\mathrm{n} / \mathrm{a}$ & $\mathrm{n} / \mathrm{a}$ \\
\hline
\end{tabular}

* Indicates significance testing between sepsis hospitalization and non-sepsis hospitalization group, the population-based cohort is described for comparison only; ${ }^{\dagger}$ The 2006 Census gathered information on whether a person identified with the Aboriginal peoples of Canada. In this document, the term "Indigenous” is used in place of “Aboriginal”; ¥ Included mechanical ventilation, tracheostomy, dialysis, endoscopy, and heart resuscitation-see eTable 3 (available as ESM)

$\mathrm{CI}=$ confidence interval, $\mathrm{IQR}=$ interquartile range 
Table 2 Crude and age-standardized rates of sepsis per 100,000 population by Census characteristics, 2006 Census-Discharge Abstract Database study cohort, Canada excluding Quebec, 2006/2007 through 2008/2009

\begin{tabular}{|c|c|c|c|}
\hline Variable & $\begin{array}{l}\text { Crude average annual rate of sepsis } \\
\text { hospitalization, per } 100,000 \text { population } \\
(95 \% \mathrm{CI})\end{array}$ & $\begin{array}{l}\text { Age-standardized average annual rate of sepsis } \\
\text { hospitalization, per } 100,000 \text { population }(95 \% \mathrm{CI})\end{array}$ & \\
\hline Overall sepsis rate & 97 (96 to 98$)$ & 96 (95 to 97$)$ & \\
\hline Severe sepsis rate & $38(37$ to 38$)$ & 37 (37 to 38$)$ & \\
\hline \multicolumn{4}{|l|}{ Sex } \\
\hline Female & 85 (84 to 86$)$ & 79 (78 to 80$)$ & $P<0.001^{\dagger}$ \\
\hline Male & $109(107$ to 110$)$ & 118 (116 to 119$)$ & ref \\
\hline \multicolumn{4}{|l|}{ Age group } \\
\hline $18-34$ & $15(14$ to 16$)$ & $\mathrm{n} / \mathrm{a}$ & \\
\hline $35-44$ & 29 (28 to 30$)$ & $\mathrm{n} / \mathrm{a}$ & \\
\hline $45-54$ & 56 (54 to 57$)$ & $\mathrm{n} / \mathrm{a}$ & \\
\hline $55-64$ & $128(125$ to 130$)$ & $\mathrm{n} / \mathrm{a}$ & \\
\hline $65-74$ & 248 (243 to 252$)$ & $\mathrm{n} / \mathrm{a}$ & \\
\hline $75-84$ & 413 (406 to 421$)$ & $\mathrm{n} / \mathrm{a}$ & \\
\hline 85 and older & 506 (491 to 521$)$ & $\mathrm{n} / \mathrm{a}$ & \\
\hline \multicolumn{4}{|l|}{ Income } \\
\hline Quintile 1 (lowest) & $119(116$ to 121$)$ & $126(124$ to 129$)$ & $P<0.001$ \\
\hline Quintile 2 & 131 (129 to 133$)$ & 105 (103 to 107$)$ & $P<0.001$ \\
\hline Quintile 3 & 103 (101 to 105$)$ & $98(96$ to 100$)$ & $P<0.001$ \\
\hline Quintile 4 & 79 (77 to 80$)$ & $87(85$ to 89$)$ & $P<0.001$ \\
\hline Quintile 5 (highest) & $64(63$ to 66$)$ & $79(77$ to 81$)$ & ref \\
\hline \multicolumn{4}{|l|}{ Education } \\
\hline $\begin{array}{l}\text { Did not graduate from high } \\
\text { school }\end{array}$ & 185 (182 to 187$)$ & $121(119$ to 123$)$ & $P<0.001$ \\
\hline $\begin{array}{l}\text { Graduated from high school } \\
\text { and more }\end{array}$ & 75 (74 to 76$)$ & 89 (88 to 90$)$ & ref \\
\hline \multicolumn{4}{|l|}{ Marital status } \\
\hline Never married & 41 (40 to 42$)$ & 115 (110 to 118$)$ & $P<0.001$ \\
\hline Married & 119 (118 to 120$)$ & 94 (93 to 95$)$ & ref \\
\hline \multicolumn{4}{|l|}{ Visible minority groups } \\
\hline Not a visible minority & 103 (102 to 104$)$ & 96 (95 to 97$)$ & ref \\
\hline Chinese & 54 (51 to 57$)$ & 64 (61 to 68$)$ & $P<0.001$ \\
\hline South Asian & 67 (63 to 70$)$ & 93 (88 to 98$)$ & $P=0.26$ \\
\hline Black & $65(60$ to 70$)$ & 95 (87 to 102$)$ & $P=0.77$ \\
\hline $\begin{array}{l}\text { Korean, Filipino, Japanese, } \\
\text { Southeast Asian, Arab, West } \\
\text { Asian }\end{array}$ & 59 (56 to 62$)$ & 92 (87 to 98$)$ & $P=0.22$ \\
\hline Other & 107 (103 to 111$)$ & $150(143$ to 156$)$ & $P<0.001$ \\
\hline \multicolumn{4}{|l|}{ Indigenous identity $^{\dagger}$} \\
\hline Yes & 138 (133 to 144$)$ & $183(175$ to 190$)$ & $P<0.001$ \\
\hline No & 95 (94 to 96$)$ & 94 (93 to 94$)$ & ref \\
\hline \multicolumn{4}{|l|}{ Immigrant status } \\
\hline Yes & $104(102$ to 105$)$ & 88 (87 to 89$)$ & $P<0.001$ \\
\hline No & 94 (93 to 95$)$ & $100(98$ to 101$)$ & ref \\
\hline \multicolumn{4}{|l|}{ Functional limitations } \\
\hline None & $50(49$ to 51$)$ & $64(63$ to 65$)$ & ref \\
\hline Sometimes & 243 (238 to 248 ) & 144 (141 to 148$)$ & $P<0.001$ \\
\hline Often & 447 (440 to 454$)$ & $291(285$ to 298$)$ & $P<0.001$ \\
\hline
\end{tabular}


Table 2 continued

\begin{tabular}{lll}
\hline Variable & $\begin{array}{l}\text { Crude average annual rate of sepsis } \\
\text { hospitalization, per 100,000 population } \\
(95 \% \mathrm{CI})\end{array}$ & $\begin{array}{l}\text { Age-standardized average annual rate of sepsis } \\
\text { hospitalization, per 100,000 population (95\% CI) }\end{array}$ \\
\hline $\begin{array}{l}\text { Employment } \\
\text { Employed }\end{array}$ & $39(38$ to 39$)$ & $72(70$ to 75$)$ \\
Not employed & $48(45$ to 51$)$ & $116(102$ to 131$)$ \\
Not in the labour force & $225(222$ to 227$)$ & 135 (134 to 137$)$ \\
$\begin{array}{l}\text { Living in an urban location } \\
\text { Yes }\end{array}$ & $95(94$ to 96$)$ & $96(95$ to 97$)$ \\
No & $102(99$ to 104$)$ & $97(95$ to 98$)$ \\
\hline
\end{tabular}

* Indicates significance testing within the categories of age-standardized rates, $P$ values for variables with multiple categories were corrected using the Bonferroni adjustment; ref indicates the comparison group; ${ }^{\dagger}$ the original variable was dichotomized to Indigenous identity $v s$ no Indigenous identity for the calculation of rates and multivariable modelling because the sample size in some cells was too small to allow for reliable estimates

$\mathrm{CI}=$ confidence interval. These data were age-standardized to the 2006 Canadian standard population

\section{Discussion}

We identified more than 10,000 patients aged $18 \mathrm{yr}$ and older who were admitted to hospital with sepsis between fiscal years 2006/2007 and 2008/2009 (excluding Quebec), who were successfully linked to the 2006 long-form Canadian Census. This sample represented a weighted count of approximately 49,000 Canadians from all provinces and territories, excluding Quebec. The overall average annual age-standardized rate of sepsis hospitalization was 96 cases/100,000 population; of these almost $40 \%$, or 37 cases $/ 100,000$ population, were classified as severe sepsis. The association of Census characteristics with sepsis hospitalization varied with age. In age-specific hospital admission models several characteristics were consistently associated with an increased odds of hospital admission with sepsis including increasing age, male sex, never being married, visible minority status, having functional limitations, and not being in the labour force. This study also showed that sepsis remains a considerable burden for individual patients and the healthcare system, with in-hospital mortality rates among patients admitted with sepsis approximately ten-times higher than for those admitted for all other reasons (except for birth-related admissions).

Census variables identified as risk factors for admission with sepsis in this analysis, would not otherwise have been identified, given the limited socio-demographic information available in administrative data sets. The breadth of the data collected in the Census allows for analysis across multiple social determinants of health, enabling the identification of risk factors and risk groups in which to target future primary and secondary sepsis prevention strategies. ${ }^{20}$ These findings lend support to the importance of variables measured in Census data (linked to hospitalization data), not only for population health surveillance of chronic conditions, but also for their potential importance in the surveillance of acute lifethreatening critical illnesses like sepsis.

Our findings in relation to overall and severe sepsis rates are consistent with those produced by CIHI and Husak et al., ${ }^{3,4}$ using the full DAD (excluding Quebec) over the same time period. Nevertheless, in a recent meta-analysis Fleischmann et al. found considerably higher rates of sepsis and severe sepsis in seven high-income countries (not including Canada). ${ }^{2}$ This can be explained by differences in study design, in particular the methods used to ascertain cases of sepsis/severe sepsis. Fleischmann noted that studies included in their meta-analysis used both clinical criteria and ICD $9 / 10$ code-based criteria to identify cases. $^{2}$ This led to considerable heterogeneity in the estimates, which was also highlighted recently by both Jolley et al. and Mariansdatter et al. ${ }^{11,33}$ Both authors noted that, even in code-based analyses, ICD-9/10 coding schemes varied from study to study. ${ }^{11,33}$ The World Health Assembly also emphasized the issue of ICD coding by urging stakeholders "to apply and improve the use of the International Classification of Diseases system to establish the prevalence and profile of sepsis...". ${ }^{10}$ While an expanded ICD-10 definition of sepsis has been developed in Canada, ${ }^{12}$ we wanted to benchmark our findings to those of CIHI and Husak et al., ${ }^{3,4}$ as a validation of the Census-linked data. The benefit of the Census-linked data is that they can be used in combination with evolving ICD-10 (or future ICD versions) code-based definitions of sepsis. Indeed, the ICD-11 coding scheme has been developed by the WHO with the aim of providing far more granular information compared with the ICD-10, ${ }^{34}$ and will presumably improve case ascertainment of sepsis. 
Table 3 Socio-demographic factors associated with sepsis hospitalization compared with hospitalization for other reasons. Agestratified logistic multivariable adjusted regression models, 2006

Characteristic Model 1: Age strata 18-34 yr odds ratio $(95 \% \mathrm{CI})$

$1.019(1.008 \text { to } 1.029)^{*}$

Age (continuous)

Sex

\section{Male}

Female

Income

Quintile 1 (lowest)

Quintile 2-5

Education

Did not graduate from high school

Graduated from high school and more ref

Marital status

Never married

Married

Self-reported visible minority status

Not a visible minority

Visible minority

Indigenous identity ${ }^{\dagger}$

No

Yes

ref

1.08 (0.89 to 1.30$)$

Immigrant status

No

Yes

ref

1.04 (0.89 to 1.22$)$

ref

$2.80(2.51 \text { to } 3.12)^{*}$

ref

1.76 (1.59 to 1.94$)^{*}$

ref

0.89 (0.81 to 1.00$)$ yr Model 2: Age strata 35-64 yr Model 3: Age strata $65 \mathrm{yr}$ and older

Census-Discharge Abstract Database study cohort, Canada excluding Quebec, 2006/2007 through 2008/2009 odds ratio $(95 \% \mathrm{CI}) \quad$ odds ratio $(95 \% \mathrm{CI})$

$1.027(1.025 \text { to } 1.029)^{*}$

$1.002(1.001$ to 1.004$) *$

1.40 (1.36 to 1.44$)^{*}$

ref

$1.52(1.48 \text { to } 1.56)^{*}$

ref

1.15 (1.11 to 1.19$)^{*}$

ref

$1.02(0.99$ to 1.06$)$

ref

$1.06(1.03 \text { to } 1.10)^{*}$

ref

1.08 (1.05 to 1.10$)^{*}$

ref

$1.33(1.27 \text { to } 1.38)^{*}$

ref

$1.13(1.07 \text { to } 1.20)^{*}$

ref

ref

$1.26(1.19 \text { to } 1.34)^{*}$

ref

ref

$1.22(1.13 \text { to } 1.32)^{*}$

ref

ref

$1.00(0.96$ to 1.05$)$

ref

1.15 (1.11 to 1.18$)^{*}$

ref

ref

1.73 (1.67 to 1.78 )*

$1.42(1.38 \text { to } 1.45)^{*}$

ref

$1.48(1.43 \text { to } 1.53)^{*}$

ref

1.13 (1.08 to 1.19$)^{*}$

ref

ref

$1.20(1.16 \text { to } 1.25)^{*} \quad 1.22(1.18 \text { to } 1.26)^{*}$

*Denotes a statistically significant result compared with the reference category. ${ }^{\dagger}$ The original variable was dichotomized to Indigenous identity $v s$ no Indigenous identity for the calculation of rates and multivariable modelling because the sample size in some cells was too small to allow for reliable estimates

$\mathrm{CI}=$ confidence interval; ref $=$ reference category

Benchmarking against previous national estimates, our analysis showed that the rates of sepsis varied by Census characteristics beyond age and sex. These characteristics were further investigated in age-stratified multivariable logistic models, and the association we found between visible minority status and sepsis hospitalization can be compared with several other studies that have examined sepsis incidence by ethnicity and race in the United States. ${ }^{28,35,36}$ Both Dombrovskiy et al. and Martin et al. reported variation in the incidence of sepsis hospitalization, with rates among non-whites almost double those of whites in population-based studies. ${ }^{28,35} \mathrm{~A}$ population-based study by Barnato et al. obtained mixed findings in relation to race; they found that black race was associated with higher incidence of sepsis, whereas Hispanic ethnicity was associated with lower incidence after adjustment for arealevel poverty and rurality. ${ }^{36}$ In contrast, Moore et al. ${ }^{37}$ showed that the odds of first sepsis incidence was similar between black and white participants in the REasons for 
Table 4 Hospital length of stay and outcomes of 2006 long-form Census respondents hospitalized for sepsis compared with those hospitalized for other reasons, 2006 Census-Discharge Abstract Database study cohort, Canada excluding Quebec, 2006/2007 through 2008/2009

\begin{tabular}{|c|c|c|c|}
\hline Variable & $\begin{array}{l}\text { Sepsis hospitalizations }(n=10,400 \\
\text { individuals) }\end{array}$ & $\begin{array}{l}\text { Non-sepsis hospitalizations ( } n=406,000 \\
\text { individuals) }\end{array}$ & \\
\hline \multicolumn{4}{|l|}{ Mortality } \\
\hline Hospital mortality counts ${ }^{\dagger}$ & 3,200 & 11,800 & \\
\hline $\begin{array}{l}\text { Hospital mortality counts, weighted count } \\
\qquad(95 \% \mathrm{CI})\end{array}$ & $15,665(15,064$ to 16,265$)$ & $58,997(57,839$ to 60,154$)$ & \\
\hline Crude hospital mortality rate, $\%(95 \% \mathrm{CI})$ & $31.95(31.54$ to 32.37$)$ & $3.03(3.00$ to 3.05$)$ & $P<0.001^{*}$ \\
\hline \multicolumn{4}{|l|}{ Age-specific hospital mortality rate, $\%(95 \% \mathrm{CI})$} \\
\hline $18-34 \mathrm{yr}$ & $9.48(6.42$ to 13.79$)$ & $0.31(0.25$ to 0.37$)$ & $P<0.001$ \\
\hline $25-64 \mathrm{yr}$ & $23.21(21.76$ to 24.73$)$ & $1.20(1.15$ to 1.26$)$ & $P<0.001$ \\
\hline $65 \mathrm{yr}$ and older & 39.31 (37.94 to 40.72$)$ & $5.82(5.69$ to 5.94$)$ & $P<0.001$ \\
\hline \multicolumn{4}{|l|}{ Discharge disposition } \\
\hline \multicolumn{4}{|c|}{ Discharge disposition among patients discharged alive, \% (95\% CI) } \\
\hline Home & $50.08(49.54$ to 50.62$)$ & 78.04 (77.89 to 78.19$)$ & $P<0.001$ \\
\hline Home with services & 20.54 (20.11 to 20.98$)$ & $10.71(10.59$ to 10.82$)$ & $P<0.001$ \\
\hline Acute care/other facility & $17.47(17.07$ to 17.88$)$ & $5.74(5.66$ to 5.82$)$ & $P<0.001$ \\
\hline Long-term care & $11.09(10.76$ to 11.44$)$ & $4.68(4.61$ to 4.75$)$ & $P<0.001$ \\
\hline Other & $0.80(0.71$ to 0.90$)$ & $0.83(0.79$ to 0.86$)$ & $P=0.82$ \\
\hline \multicolumn{4}{|l|}{ Special care unit admission and length of stay } \\
\hline $\begin{array}{l}\text { Admitted to a special care unit, \% (95\% } \\
\text { CI) }\end{array}$ & $45.61(44.53$ to 46.68$)$ & $11.97(11.85$ to 12.07$)$ & $P<0.001$ \\
\hline $\begin{array}{l}\text { Special care unit length of stay, median } \\
\text { [IQR] }\end{array}$ & $5.42[2.08-12.66]$ & $2.08[1.04-4.04]$ & \\
\hline Hospital length of stay, median [IQR] & $10[4-23]$ & $3[2-6]$ & \\
\hline
\end{tabular}

* Indicates significance testing between sepsis hospitalization and non-sepsis hospitalization group; ${ }^{\dagger}$ Unweighted counts were rounded to the nearest hundred

$\mathrm{CI}=$ confidence interval, $\mathrm{IQR}=$ interquartile range

Geographic And Racial Differences in Stroke (REGARDS) cohort study.

In this study, employment, education, and income (albeit among 35-64 yr olds only), were also associated with an increased odds of hospitalization for sepsis. These findings are very similar to those of Storm et al. ${ }^{38}$ who found, in a small Danish case-control study, that individuals with lower levels of education and those not in the labour force had significantly higher risks of intensive care unit admission for sepsis. As well, these findings are indirectly supported by those of Moore et al. ${ }^{15}$ who showed that sepsis mortality was clustered in three major regions in the southern United States, which were more likely to have lower education levels, higher poverty levels, higher unemployment rates, and a high proportion of medically uninsured individuals. More recently, Donnelly et al..$^{39}$ showed, with mediation analysis, that physical weakness, individual income, and comorbid diabetes may partially explain differential infection risks by neighbourhood socioeconomic status in the United States.

The association of Indigenous identity with increased odds of sepsis hospitalization in two of our age-specific models is consistent with findings by Carrière et al. ${ }^{18,40}$ who reported overall higher rates of hospitalization for all causes among those of Indigenous identity in Canada, using the same data source as our study. These authors noted that inequalities in social determinants of health may influence hospitalization rate disparities, because in many First Nations communities, municipal infrastructure is inadequate $^{41}$; educational and employment opportunities are limited; and the prevalence of low income is high. ${ }^{42}$ As well, other Canadian studies have shown that both the incidence of critical illness in general, as well as severe trauma and injury are higher among Indigenous Canadians. ${ }^{43-46}$ Similarly in Australia, Davis et al ${ }^{47}$ have shown higher rates of sepsis incidence, but lower mortality rates among Indigenous Australians in the tropical Northern Territories.

The results of this study, combined with the existing literature discussed above, indicate that socio-demographic characteristics, in addition to already established risk factors, are important determinants of sepsis incidence and hospitalization. These results are relevant for policy makers interested in developing data sources for sepsis 
surveillance as well as clinicians interested in addressing the distal determinants of sepsis and approaching sepsis as a preventable public health problem. ${ }^{20}$ This means conceptualizing sepsis as a problem that can be treated with population and system-based solutions, such as those suggested by Kempker et al., including management of risk factors, appropriate antibiotic prophylaxis, public awareness, hygiene, and immunization. ${ }^{20}$

\section{Limitations}

This study should be considered in the context of its limitations. The ascertainment of socio-demographic variables in the Census is cross-sectional. While the study period was relatively short, is it possible that individuals' socio-demographic information changed between Census day and the date of hospitalization. Validation of the linked files used in this study showed that not all hospitalizations were represented. ${ }^{17}$ In particular, there was lower coverage of some populations, for instance among 15-24 yr olds, those living in the territories, and Indigenous populations, which may lead to under ascertainment of sepsis in these groups. As well, all Indigenous identities were grouped for analysis because of small sample sizes. This grouping may mask important differences between distinct groups of Indigenous people.

Hospitalization data were not available for the province of Quebec, which is the second most populous province in Canada. As well, the institutionalized population is not represented in the Census. Although the Census data are from 2006, it was the most recent Census-linked file available at the time of analysis; it is unlikely that the results would differ if more recent Census data were available because socio-demographic characteristics, as well as interrelationships between socio-demographic characteristics and health outcomes, are relatively stable over short periods of time. Nevertheless, it is possible that the case-mix of patients admitted to Canadian hospitals has changed over time. In addition, the accuracy of sepsis coding in the hospital administrative data may have changed because of increasing public and professional awareness of sepsis. Future analyses could take advantage of additional population-based data as well as electronic health record data that are becoming available for linkage, for future surveillance of sepsis and other critical illnesses.

\section{Conclusions}

Using linked population-based data, we were able to identify a large sample of Canadians who are hospitalized for sepsis. This data source affords a unique opportunity to examine in more detail the socio-demographic characteristics of patients admitted to hospital with sepsis. Such data could be helpful for epidemiological surveillance, as well as primary prevention, and can be used in combination with evolving administrative data definitions of sepsis.

Author contributions All authors were involved in the conception, design, and interpretation of the research. Deirdre A. Hennessy acquired the data. Deirdre A. Hennessy and Andrea Soo analyzed the data. Deirdre A. Hennessy drafted the manuscript and all other authors were involved in revising the final version. All authors agree to be accountable for their own contributions and to ensure that questions related to the accuracy or integrity of any part of the work, even ones in which the author was not personally involved, are appropriately investigated, resolved, and the resolution documented in the literature.

Acknowledgements The authors acknowledge Gisele Carrière of the Health Analysis Division, Statistics Canada for providing advice and guidance about the Census-linked data. The authors also acknowledge Evelyne Bougie of the Health Analysis Division, Statistics Canada for her review of an earlier draft of the manuscript.

\section{Conflicts of interest None.}

Funding statement This research was funded by the Health Analysis Division, Statistics Canada and the Department of Critical Care, University of Calgary.

Editorial responsibility This submission was handled by Dr. Sangeeta Mehta, Associate Editor, Canadian Journal of Anesthesia.

\section{References}

1. Vincent JL, Opal SM, Marshall JC, Tracey KJ. Sepsis definitions: time for change. Lancet 2013; 381: 774-5.

2. Fleischmann C, Scherag A, Adhikari NK, et al.; International Forum of Acute Care Trialists. Assessment of global incidence and mortality of hospital-treated sepsis. Am J Respir Crit Care Med 2016; 193: 259-72.

3. Canadian Institute for Health Information. In Focus: A National Look at Sepsis - 2009. Available from URL: https://secure.cihi. ca/free_products/HSMR_Sepsis2009_e.pdf (accessed October 2019).

4. Husak L, Marcuzzi A, Herring J, et al. National analysis of sepsis hospitalizations and factors contributing to sepsis in-hospital mortality in Canada. Healthc Q 2010; 31: 35-41.

5. Navaneelan T, Alam S, Peters PA, Phillips O. Health at a Glance - Death involving sepsis in Canada - January 2016. Available from URL: https://www150.statcan.gc.ca/n1/pub/82-624-x/ 2016001/article/14308-eng.htm (accessed October 2019).

6. Iwashyna TJ, Ely EW, Smith DM, Langa KM. Long-term cognitive impairment and functional disability among survivors of severe sepsis. JAMA 2010; 304: 1787-94.

7. Jones TK, Fuchs BD, Small DS, et al. Post-acute care use and hospital readmission after sepsis. Ann Am Thorac Soc 2015; 12 : 904-13. 
8. Reinhart K, Daniels R, Kissoon N, Machado FR, Schachter RD, Finfer $S$. Recognizing sepsis as a global health priority - a WHO resolution. N Engl J Med 2017; 377: 414-7.

9. Finfer S, Machado FR. The global epidemiology of sepsis: does it matter that we know so little? Am J Respir Crit Care Med 2016; 193: 228-30.

10. The Seventieth World Health Assembly. Improving the Prevention, Diagnosis and Clinical Management of Sepsis. Agenda item 12.2. Geneva, 2017. Available from URL: http:// apps.who.int/gb/ebwha/pdf_files/WHA70/A70_R7-en.pdf (accessed October 2019).

11. Jolley RJ, Sawka KJ, Yergens DW, Quan H, Jetté N, Doig CJ. Validity of administrative data in recording sepsis: a systematic review. Crit Care 2015. https://doi.org/10.1186/s13054-0150847-3.

12. Jolley RJ, Quan H, Sawka KJ, et al. Validation and optimisation of an ICD-10-coded case definition for sepsis using administrative health data. BMJ Open 2015; 5: e009487.

13. Rudd KE, Delaney A, Finfer S. Counting sepsis, an imprecise but improving science. JAMA 2017; 318: 1228-9.

14. Rhee C, Dantes R, Epstein L, et al.; CDC Prevention Epicenter Program. Incidence and trends of sepsis in US hospitals using clinical vs claims data, 2009-2014. JAMA 2017; 318: 1241-9.

15. Moore JX, Donnelly JP, Griffin R, Howard G, Stafford MM, Wang HE. Defining sepsis mortality clusters in the United States. Crit Care Med 2016; 44: 1380-7.

16. Wang HE, Devereaux RS, Yealy DM, Stafford MM, Howard G. National variation in United States sepsis mortality: a descriptive study. Int J Health Geogr 2010. https://doi.org/10.1186/1476072X-9-9.

17. Rotermann M, Sanmartin C, Trudeau R, St-Jean H. Linking 2006 Census and hospital data in Canada. Health Rep 2015; 26: 10-20.

18. Carrière $G$, Bougie $E$, Kohen D, Rotermann M, Sanmartin C. Acute care hospitalization by Aboriginal identity, Canada, 2006 through 2008. Health Rep 2016; 27: 3-11.

19. Ng E, Sanmartin C, Tu JV, Manuel DG. All-cause and circulatory disease-related hospitalization, by generation status: evidence from linked data. Health Rep 2015; 26: 3-9.

20. Kempker JA, Wang HE, Martin GS. Sepsis is a preventable public health problem. Crit Care 2018. https://doi.org/10.1186/s13054018-2048-3.

21. Statistics Canada. Directive on Microdata Linkage - 2017. Available from URL: https://www.statcan.gc.ca/eng/record/ policy4-1 (accessed October 2019).

22. Statistics Canada. 2006 Census of Population - 2009. Available from URL: https://www12.statcan.gc.ca/census-recensement/ 2006/ref/index-eng.cfm (accessed October 2019).

23. Statistics Canada. 2006 Census Technical Report: Coverage 2009. Available from URL: https://www12.statcan.gc.ca/censusrecensement/2006/ref/rp-guides/rp/coverage-couverture/cov-couv_ index-eng.cfm (accessed October 2019).

24. Canadian Institute for Health Information. Discharge Abstract Database (DAD) Metadata. Available from URL: https://www. cihi.ca/en/discharge-abstract-database-metadata (accessed October 2019).

25. Canadian Institute for Health Information. CIHI Data Quality of the 2006-2007, 2007-2008, and 2008-2009 Discharge Abstract Database. Available from URL: https://secure.cihi.ca/estore/ productSeries.htm?pc=PCC228 (accessed October 2019).

26. Angus DC, Linde-Zwirble WT, Lidicker J, Clermont G, Carcillo $J$, Pinsky MR. Epidemiology of severe sepsis in the United States: analysis of incidence, outcome, and associated costs of care. Crit Care Med 2001; 29: 1303-10.

27. Dombrovisky VY, Martin AA, Sunderram J, Paz HL. Rapid increase in hospitalization and mortality rate for severe sepsis in the United States: a trend analysis from 1993 to 2003. Crit Care Med 2007; 35: 1244-50.

28. Martin GS, Mannino DM, Eaton S, Moss M. The epidemiology of sepsis in the United States from 1979 through 2000. N Engl J Med 2003; 348: 1546-54.

29. Gushulak BD, Pottie K, Hatcher Roberts J, Torres S, DesMeules M; Canadian Collaboration for Immigrant and Refugee Health. Migration and health in Canada: health in the global village. CMAJ 2011; 183: E952-8.

30. Raphael D. Social Determinants of Health: Canadian Perspectives. Toronto: Canadian Scholar's Press Inc.; 2004.

31. Roberts $G$. Analyzing census microdata in an RDC: What weight to use? The Research Data Centres Information and Technical Bulletin. Statistics Canada 2012; 5 (1). Available from URL: www.statcan.gc.ca/pub/12-002-x/2012001/article/11642-eng.htm (accessed October 2019).

32. Statistics Canada. 2006 Census Technical Report on Sampling and Weighting - 2009. Available from URL: https://www12. statcan.gc.ca/census-recensement/2006/ref/rp-guides/rp/sw-ep/swep_index-eng.cfm (accessed October 2019).

33. Mariansdatter SE, Eiset AH, Søgaard KK, Christiansen CF. Differences in reported sepsis incidence according to study design: a literature review. BMC Med Res Methodol 2016. https://doi.org/10.1186/s12874-016-0237-9.

34. Anonymous. ICD-11. Editorial. Lancet 2019; 393: 2275. Available from URL: https://www.thelancet.com/pdfs/journals/ lancet/PIIS0140-6736(19)31205-X.pdf (accessed October 2019).

35. Dombrovskiy VY, Martin AA, Sunderram J, Paz HL. Occurrence and outcomes of sepsis: influence of race. Crit Care Med 2007; 35: 763-8.

36. Barnato AE, Alexander SL, Linde-Zwirble WT, Angus DC. Racial variation in the incidence, care, and outcomes of severe sepsis: analysis of population, patient, and hospital characteristics. Am J Respir Crit Care Med 2008; 177: 279-84.

37. Moore JX, Donnelly JP, Griffin R, et al. Black-white racial disparities in sepsis: a prospective analysis of the REasons for Geographic And Racial Differences in Stroke (REGARDS) cohort. Crit Care 2015. https://doi.org/10.1186/s13054-0150992-8.

38. Storm L, Schnegelsberg A, Mackenhauer J, Andersen LW, Jessen $M K$, Kirkegaard $H$. Socioeconomic status and risk of intensive care unit admission with sepsis. Acta Anaesthesiol Scand 2018; 62: 983-92.

39. Donnelly JP, Lakkur S, Judd SE, et al. Association of neighbourhood socioeconomic status with risk of infection and sepsis. Clin Infect Dis 2018; 66: 1940-7.

40. Carrière G, Bougie E, Kohen D. Acute care hospitalization for mental and behavioural disorders among First Nations people. Health Rep 2018; 29: 11-9.

41. Standing Senate Committee on Aboriginal Peoples. On-Reserve Housing and Infrastructure: Recommendations for Change. Ottawa, 2015. Available from URL: http://www.parl.gc.ca/ Content/SEN/Committee/412/appa/rep/rep12jun15-e.pdf (accessed August October 2019)

42. Statistics Canada. 2006 Census of Canada: Special Interest Profiles. Ottawa, 2009. Available from URL: https://www12.statcan.gc.ca/ census-recensement/2006/dp-pd/prof/sip/Rp-eng.cfm?LANG= $\mathrm{E} \& \mathrm{APATH}=3 \& \mathrm{DETAIL}=0 \& \mathrm{DIM}=0 \& \mathrm{FL}=\mathrm{A} \& \mathrm{FREE}=0 \& \mathrm{GC}=$ $0 \& \mathrm{GID}=0 \& \mathrm{GK}=0 \& \mathrm{GRP}=1 \& \mathrm{PID}=97446 \& \mathrm{PRID}=0 \& \mathrm{PTYPE}=$ $97154 \& S=0 \&$ SHOWALL $=0 \&$ SUB $=0 \&$ Temporal $=2006 \&$ THEME $=$ $73 \&$ VID $=0 \&$ VNAMEE $=\&$ VNAMEF (accessed October 2019).

43. Laupland KB, Karmali S, Kirkpatrick AW, Crowshoe L, Hameed $S M$. Distribution and determinants of critical illness among status Aboriginal Canadians. A population-based assessment. J Crit Care 2006; 21: 243-7. 
44. Karmali $S$, Laupland $K$, Harrop AR, et al. Epidemiology of severe trauma among status Aboriginal Canadians: a populationbased study. CMAJ 2005; 172: 1007-11.

45. Brussoni M, George MA, Jin A, Lalonde CE, McCormick $R$. Injuries to Aboriginal populations living on- and off-reserve in metropolitan and non-metropolitan areas in British Columbia, Canada: incidence and trends, 1986-2010. BMC Public Health 2016. https://doi.org/10.1186/s12889-016-3078-x.

46. Jin A, Brussoni M, George MA, Lalonde CE, McCormick R. Risk of hospitalization due to unintentional fall injury in British Columbia, Canada, 1999-2008: ecological associations with socioeconomic status, geographic place, and Aboriginal ethnicity. J Racial Ethn Health Disparities 2017; 4: 558-70.

47. Davis JS, Cheng AC, McMillan M, Humphrey AB, Stephens DP, Anstey NM. Sepsis in the tropical top end of Australia's Northern Territory: disease burden and impact on Indigenous Australians. Med J Aust 2011; 194: 519-24.

Publisher's Note Springer Nature remains neutral with regard to jurisdictional claims in published maps and institutional affiliations. 